\title{
CAROLINE CALLARD, Le temps des fantômes
}

\section{Virginia Melotto}

\section{(2) OpenEdition \\ Journals}

\section{Edizione digitale}

URL: https://journals.openedition.org/studifrancesi/44948

DOI: $10.4000 /$ studifrancesi.44948

ISSN: 2421-5856

\section{Editore}

Rosenberg \& Sellier

\section{Edizione cartacea}

Data di pubblicazione: 1 août 2021

Paginazione: 364-365

ISSN: 0039-2944

\section{Notizia bibliografica digitale}

Virginia Melotto, "CARoline CallaRd, Le temps des fantômes», Studi Francesi [Online], 194 (LXV | II) | 2021, online dal 01 septembre 2021, consultato il 15 octobre 2022. URL: http://journals.openedition.org/ studifrancesi/44948; DOI: https://doi.org/10.4000/studifrancesi.44948

Questo documento è stato generato automaticamente il 15 octobre 2022.

\section{(c) (i) ()}

Creative Commons - Attribuzione - Non commerciale - Non opere derivate 4.0 Internazionale - CC BYNC-ND 4.0

https://creativecommons.org/licenses/by-nc-nd/4.0/ 


\title{
CAROLINE CALLARD, Le temps des fantômes
}

\author{
Virginia Melotto
}

\section{NOTIZIA}

CAROLINE CALLARD, Le temps des fantômes, Paris, Fayard, 2019, 366 pp.

1 Muovendo da una prospettiva di affrancamento dalla teoria di Max Weber sulla formazione del pensiero moderno, il volume si interroga sulle cause storicoantropologiche e socio-politiche che hanno determinato il perdurare della figura dello spettro nell'immaginario occidentale. La figura in questione è osservata tra il XVI e il XVII secolo, periodo che la teoria di Weber indentifica come il motore del processo di razionalizzazione e di disincanto alla base della modernità, in particolare a partire dalla riforma protestante. Il territorio preso in esame è l'Europa, con un'apertura all'America del primo periodo coloniale. Il volume si articola in nove capitoli, che esaminano il motivo dello spettro da diverse angolazioni, ad esempio come figura di luogo, di legame sociale, di risoluzione dei conflitti e di paura, ma anche come figura di rottura sul piano teologico e di rinnovamento del pensiero scettico e razionale. Elemento di scontro nelle guerre di religione, la possibilità per le anime del purgatorio di tornare a far visita ai viventi viene subito contestata dai protestanti in quanto concetto nato al fine di legittimare e incrementare la vendita delle indulgenze. Oltre alle questioni prettamente teologiche, il volume si interessa anche all'evoluzione del sistema giuridico dei territori presi in esame. La presenza di apparizioni di vario tipo negli atti di processo sottolinea la centralità dello spettro nelle questioni economiche e sociali. A partire dalla fine del Seicento, il progressivo affermarsi di un pensiero scientifico e razionale porta all'estromissione dei fantasmi dai tribunali europei, nonché a un'operazione di disincanto che non arriva tuttavia a eliminarne la presenza dalla cultura occidentale. Oltre agli atti di processo, le altre fonti, peraltro non copiose, consistono in libelli e volumi che raccolgono storie di fantasmi e, in particolare, nel trattato del giurista 
Pierre Le Loyer, Discours et histoire des spectres (1586). Le temps des fantômes si conclude con una breve presentazione della riflessione sui fantasmi nel Settecento, secolo durante il quale il rifiuto dello spettro denota un atteggiamento di anticonformismo filosofico e durante il quale emergono diverse tendenze. Nel suo insieme, il volume mostra come la figura spettrale sia profondamente legata alle vicende storiche, politiche e religiose di Cinquecento e Seicento e come essa abbia saputo evolversi per sopravvivere fino ai giorni nostri, dando prova di un fascino sempre attuale, nonché di una funzione sociale e antropologica che non si è ancora esaurita. 